\title{
Pengembangan Multimedia Interaktif untuk Diklat Tenaga Perawatan Listrik Aliran Atas di BPTP Sofyan Hadi
}

\author{
Ragil Prasetyo Putro, ${ }^{\square}$ \\ ${ }^{1}$ Universitas Negeri Jakarta, Jakarta, Indonesia. \\ ${ }^{2}$ Universitas Negeri Jakarta, Jakarta, Indonesia. \\ 3 Universitas Negeri Jakarta, Jakarta, Indonesia.
}

DOI: https://doi.org/10.21009/JPI.041.o9

\begin{abstract}
Article History Abstrak
Submitted: 2021

Accepted : 2021

Published : 2021

\section{Keywords}

Multimedia Interaktif,

Diklat, Model

Pengembangan $4 \mathrm{D}$,

Listrik Aliran Atas,

Balai Pelatihan Teknik

Perkeretaapian Sofyan

Hadi

Penelitian ini bertujuan untuk menghasilkan sebuah produk berupa multimedia interaktif yang akan digunakan sebagai salah satu media penunjang pembelajaran untuk diklat tenaga perawatan prasarana perkeretaapian yaitu listrik aliran atas di Balai Pelatihan Teknik Perkeretaapian Sofyan Hadi. Dalam penelitian pengembangan ini, adapun model pengembangan yang digunakan mengacu pada metode R\&D (Research and Development) dengan model pengembangan $4 \mathrm{D}$ yang dikembangkan Thiagarajan yang memiliki tahapan terdiri atas: Define (Pendefinisian), Design (Desain), Develop (Pengembangan), dan Disseminate (Penyebaran). Produk yang dikembangkan dari penelitian ini sudah melalui tahap evaluasi formatif diantaranya Expert Review, One to One, dan uji coba skala besar. Hasil dari Expert Review dari ahli media pembelajaran mendapatkan nilai 3,80 (Sangat baik). Ahli materi mendapatkan nilai sebesar 3,70 (Sangat baik). Hasil uji coba One to One mendapatkan hasil 3,60 (Sangat baik). Hasil uji coba skala besar mendapatkan hasil 3.6o (Sangat baik). Berdasarkan hasil tersebut, dapat disimpulkan bahwa produk Multimedia Interaktif untuk Diklat Tenaga Perawatan Listrik Aliran atas dinyatakan sangat baik.
\end{abstract}

\begin{abstract}
This research aims to produce a product in the form of interactive multimedia that will be used as one of the supporting media of learning for the training of railway infrastructure maintenance personnel namely upper flow electricity in Sofyan Hadi Railway Engineering Training Center. In this development research, the development model used refers to the R\&D (Research and Development) method by thiagarajan developed ${ }_{4} \mathrm{D}$ development models that have stages consisting of: Define, Design, Develop, and Disseminate. Products developed from this study have gone through formative evaluation stages including Expert Review, One to One, and large-scale trials. The results of the Expert Review from learning media experts get a score of 3.80 (Excellent).The material expert gets a value of 3.70 (Excellent). One to One trial results get 3.60 (Excellent) results. Large-scale trial results get 3.6o (Excellent) results. Based on these results, it can be concluded that the Interactive Multimedia product for the Overhead Catenary Engineering Training is expressed very well. Keywords: Interactive Multimedia, Training, 4D development models, Overhead Catenary, Sofyan Hadi Railway Engineering Training Center
\end{abstract}

\footnotetext{
$\bowtie$ Corresponding author : Ragil Prasetyo Putro

Alamat : Universita Negeri Jakarta

Jakarta, Indonesia

E-mail : ragilprasetyoputro_1215162806@mhs.unj.ac.id

(C) 2021 Universitas Negeri Jakarta
} 


\section{PENDAHULUAN}

Pelatihan merupakan salah satu elemen utama dalam membentuk dan meningkatkan kinerja seorang pegawai, karena pelatihan dapat dikatakan sebagai salah satu faktor utama dalam mengasah potensi tiap individu pegawai terutama adalah pegawai yang mengerjakan profesi khusus yang membutuhkan tahap-tahap pelatihan untuk dapat mendapatkan izin mengerjakan profesinya. Pelatihan dan pengembangan sangatlah perlu dilakukan melihat kondisi zaman yang saat ini berkembang pesat yang mana pendidikan formal yang telah dicapai saja tidak cukup untuk memenuhi kebutuhan dan tuntutan suatu pekerjaan dalam perusahaan, terutama pekerjaan yang membutuhkan keahlian khusus. Dalam proses pembelajaran diklat yang sedang berlangsung di sebuah lembaga diklat, sangat diperlukan berbagai fasilitas yang memadai sebagai bentuk sarana penunjang kegiatan pembelajaran, hal ini sebagai langkah agar kegiatan pembelajaran dalam diklat berjalan dengan baik. Adapun fasilitas yang digunakan sebagai penunjang kegiatan pembelajaran diklat sangat beragam, salah satunya adalah menggunakan media sebagai sarana belajar dalam proses pembelajaran diklat. Media pembelajaran yang dapat digunakan sendiri pun dapat berupa media cetak dan non cetak. Diklat yang terdapat di lingkungan PT Kereta Api Indonesia (Persero). Untuk membentuk pegawai PT Kereta Api Indonesia (Persero) yang kompeten serta memiliki keterampilan yang mumpuni di segala aspek maka perusahaan memiliki balai pelatihan yang tersebar di seluruh wilayah kerja PT Kereta Api Indonesia (Persero), masing-masing balai diklat memiliki jurusan atau program diklat yang berbeda-beda sesuai dengan kebutuhan dan bidang yang dimiliki oleh pegawai PT Kereta Api Indonesia (Persero).
Balai Pelatihan Teknik Perkeretaapian Sofyan Hadi (BPTP) Bekasi merupakan salah satu balai diklat yang dimiliki oleh perusahaan ini, balai diklat ini memiliki beberapa program diklat yang diberikan untuk pegawai perusahaan, BPTP Sofyan Hadi ini merupakan balai diklat yang memiliki fokus utama dalam membentuk lulusan yang mampu menguasai segala bidang tentang jalan/prasarana perkeretaapian dan masinis kereta berpenggerak listrik. Selama pelaksanaan diklat tahun 2019 di BPTP Sofyan Hadi, media yang digunakan sangat terbatas hanya pembelajaran dalam kelas dengan media presentasi dari trainer serta modul/diktat yang merupakan print out dari powerpoint presentasi saja serta media praktik langsung di ruang simulasi dan lapangan, namun untuk pembelajaran secara mandiri dan bersifat interaktif untuk mengasah pemahaman siswa di tempat tersebut belum terdapat media untuk melakukan pembelajaran mandiri untuk siswa.

Melihat pentingnya kebutuhan media untuk menunjang diklat listrik aliran atas tersebut maka diperlukan bantuan media yang dapat mengatasi permasalahan belajar yang terjadi dalam proses diklat. Hal tersebut dapat diatasi dengan mengembangkan media pembelajaran yang menyesuaikan kebutuhan diklat yang dilakukan oleh institusi. Pengembangan media pembelajaran untuk mengatasi permasalahan merupakan salah satu garapan dari teknologi pendidikan yang dimana tertulis dalam definisi teknologi pendidikan oleh AECT tahun 2004: Teknologi pendidikan adalah studi dan praktik etis memfasilitasi belajar dan meningkatkan kinerja dengan menciptakan, menggunakan dan mengelola proses dan sumber teknologi yang tepat.

Berdasarkan definisi tersebut dapat dijelaskan bahwa untuk memfasilitasi dan mempermudah proses pembelajaran atau diklat adalah dengan mengembangkan sebuah media 
pembelajaran yang berupa media interaktif yang dapat membangkitkan stimulus dan respon peserta didik selama proses pembelajaran berlangsung, media interaktif sendiri merupakan salah satu bentuk multimedia pembelajaran interaktif yang dapat digunakan untuk belajar siswa dan mengukur sejauh apa tingkat pemahaman siswa dengan materi tersebut lewat tes yang ada di dalamnya. Untuk mengembangkan multimedia ini didalamnya terdapat gambar, audio, video dan tes pemahaman serta kuis sebagai sebuah susunan yang sistemik untuk memudahkan belajar peserta didik.

\section{METODE}

Penelitian ini merupakan penelitian pengembangan atau Research and Development (R\&D) yang digunakan untuk menghasilkan sebuah produk tertentu dan menguji keefektifan produk tersebut (Sugiyono, 2016). Pada penelitian ini yang dikembangkan adalah multimedia interaktif untuk diklat tenaga perawatan listrik aliran atas. Adapun model pengembangan yang digunakan adalah model pengembangan $R \& D$ dengan metode ${ }_{4} \mathrm{D}$ yang dikembangkan oleh Thiagarajan. Model ${ }_{4} \mathrm{D}$ membagi proses pengembangannya dalam empat tahapan, yaitu; 1) Tahap pendefinisian (define), 2) tahap desain (design), tahap pengembangan (develop), dan tahap penyebaran (disseminate). Setiap langkah dalam model pengembangan ${ }_{4} \mathrm{D}$ dijelaskan secara lengkap dan sistematis sehingga memudahkan pengembang untuk mengikuti setiap tahapan yang dijabarkan.

\section{HASIL DAN PEMBAHASAN}

Pengembang melakukan tahapan dalam dalam langkah model pengembangan ${ }_{4} \mathrm{D}$, langkah pertama yang dilakukan adalah pendefinisian (define), pengembang melakukan analisis kurikulum untuk menganalisis kurikulum yang digunakan dalam diklat Listrik Aliran Atas di Balai Pelatihan Teknik Perkeretaapian Sofyan Hadi. Kemudian menganalisis peserta didik untuk menyusun bahan ajar dalam media pembelajaran agar sesuai dengan yang dibutuhkan oleh peserta didik. Yang terakhir adalah analisis materi bertujuan untuk mengidentifikasikan materi pokok yang perlu disajikan kepada peserta didik yang nantinya akan dimasukan ke dalam media pembelajaran yang dikembangkan. Selanjutnya pengembang masuk ke langkah berikutnya yaitu perancangan (design) rancangan awal dari multimedia yang akan dikembangkan. Pada tahap perancangan, pengembang membuat rancangan produk awal atau prototipe berupa storyboard. Dalam storyboard tersebut didapat kerangka perencangan media pembelajaran yang akan dikembangkan, kemudia menyiapkan perangkat pembelajaran seperti materi yang akan disusun untuk kemudian dimasukan dalam media, menyiapkan software dan hardware yang akan digunakan dalam membuat media pembelajaran. Selanjutnya masuk ke tahapan pengembangan (development) pada tahap ini dilakukan pengembangan lebih lanjut dari media yang yang sudah dirancang pada tahap sebelumnya. Tahap pengembangan ini terdapat dua kegiatan yang dilakukan, yaitu expert appraisal yang merupakan teknik untuk memvalidasi atau menilai kelayakan rancangan produk dan developmental testing yang merupakan uji coba rancangan produk pada sasaran subjek yang sesungguhnya. Adapun hasil dari expert review dari ahli yang melakukan evaluasi pada media adalah sebagai berikut:

\begin{tabular}{|c|c|c|}
\hline No & Responden & $\begin{array}{c}\text { Rilai } \\
\text { rata- } \\
\text { rata }\end{array}$ \\
\hline 1 & $\begin{array}{c}\text { Ahli Media } \\
\text { Pembelajaran }\end{array}$ & 3,80 \\
\hline 2 & $\begin{array}{c}\text { Ahli Materi } \\
\text { Pembelajaran }\end{array}$ & 3,70 \\
\hline \multicolumn{2}{|c|}{ Rata-rata Keseluruhan } & $\mathbf{3 , 7 5}$ \\
\hline
\end{tabular}

Kemudian dilanjutkan dengan uji coba One to One kepada enam responden yang merupakan siswa diklat listrik aliran atas dan menghasilkan nilai sebagai berikut:

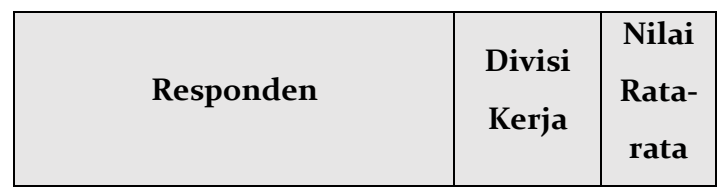


Ragil Prasetyo Putro, et.al.| JPI/Vol.o4/No.o1/2021| H. 70 - 75

\begin{tabular}{|c|l|c|}
\hline Muhammad Rivaldy & $\begin{array}{l}\text { Resor } 1.2 \\
\text { PRP }\end{array}$ & 3,65 \\
\hline Angga Ndaru Adi & $\begin{array}{l}\text { Resor } 1.8 \\
\text { MRI }\end{array}$ & 3,40 \\
\hline Wirawan Adnan & $\begin{array}{lll}\text { Resor } 1.8 \\
\text { MRI }\end{array}$ & 3,65 \\
\hline Abdul Rahman Sosa & $\begin{array}{l}\text { Resor } 1.14 \\
\text { NMO }\end{array}$ & 3,60 \\
\hline Denis Suhendar & $\begin{array}{l}\text { Resor } 1.2 \\
\text { PRP }\end{array}$ & 3,70 \\
\hline Arief Gutomo & $\begin{array}{l}\text { Resor } \\
\text { Rata-rata Keseluruhan }\end{array}$ & 3,60 \\
\hline \multicolumn{2}{|l|}{} & PSM \\
\hline
\end{tabular}

Dari hasil uji coba one to one tersebut dapat dikatakan dari dua puluh pertanyaan yang dikemukakan terhadap enam orang reponden/pengguna, didapatkan nilai rata-rata sebesar 3,6o (Sangat Baik). setelah mendapatkan masukkan dari uji coba tersebut, media akan direvisi kembali atau yang disebut revisi tahap dua, dan kembali dites kepada responden dengan jumlah banyak atau uji coba skala besar dan menghasilkan nilai sebagai berikut:

\begin{tabular}{|c|l|c|}
\hline Responden & $\begin{array}{l}\text { Divisi } \\
\text { Kerja }\end{array}$ & $\begin{array}{c}\text { Nilai } \\
\text { Rata- } \\
\text { rata }\end{array}$ \\
\hline Muhammad Rivaldy & $\begin{array}{l}\text { Resor 1.2 } \\
\text { PRP }\end{array}$ & 4,00 \\
\hline Angga Ndaru Adi & $\begin{array}{l}\text { Resor 1.8 } \\
\text { MRI }\end{array}$ & 3,50 \\
\hline Wirawan Adnan & $\begin{array}{l}\text { Resor 1.8 } \\
\text { MRI }\end{array}$ & 4,00 \\
\hline Abdul Rahman Sosa & $\begin{array}{l}\text { Resor 1.14 } \\
\text { NMO }\end{array}$ & 3,40 \\
\hline Denis Suhendar & $\begin{array}{l}\text { Resor 1.2 } \\
\text { PRP }\end{array}$ & 3,60 \\
\hline Arief Gutomo & $\begin{array}{l}\text { Resor 1.11 } \\
\text { PSM }\end{array}$ & 3,05 \\
\hline Arizal Didik Priyanto & $\begin{array}{l}\text { Resor 1.7 } \\
\text { PSE }\end{array}$ & 3,75 \\
\hline
\end{tabular}

\begin{tabular}{|c|l|c|}
\hline Sigit Deny Anjaristo & $\begin{array}{l}\text { Resor 1.7 } \\
\text { PSE }\end{array}$ & 3,30 \\
\hline Nurhaidin Saleh & $\begin{array}{l}\text { Resor 1.4 } \\
\text { THB }\end{array}$ & 3,95 \\
\hline Lucky Aditya & $\begin{array}{l}\text { Resor 1.15 } \\
\text { BSH }\end{array}$ & 3,70 \\
\hline Diego Armando & $\begin{array}{l}\text { Resor 1.5 } \\
\text { DU }\end{array}$ & 3,80 \\
\hline Fadli Topan Firdaus & $\begin{array}{l}\text { Resor 1.13 } \\
\text { BOO }\end{array}$ & 3,65 \\
\hline Mohamad Chandra Gusana & $\begin{array}{l}\text { Resor } \\
1.12 \text { DP }\end{array}$ & 3,40 \\
\hline Yudo Wiguno & $\begin{array}{l}\text { Resor 1.2 } \\
\text { PRP }\end{array}$ & 3,10 \\
\hline Sulkhan & $\begin{array}{l}\text { Resor 1.15 } \\
\text { BSH }\end{array}$ & 3,80 \\
\hline
\end{tabular}

Dari hasil uji skala besar tersebut dapat dikatakan dari dua puluh pertanyaan yang dikemukakan terhadap enam orang reponden/pengguna, didapatkan nilai rata-rata sebesar 3,60 (Sangat Baik) dan siap digunakan .

Tahapan berikutnya adalah penyebaran (disseminate) pada tahap ini media yang sudah selesai dikembangkan akan dilakukan penyebarluasan kepada pengguna untuk bisa digunakan secara lebih lanjut, disini pengembang mengunggah multimedia interaktif tersebut ke dalam sebuah hosting agar bisa digunakan secara daring di Balai Pelatihan Teknik Perkeretaapian Sofyan Hadi. Praktiknya menggunakan pola pemanfaatan secara terkontrol dengan situasi di luar kelas.

\section{SIMPULAN}

Dengan demikian maka berdasarkan prosedur tahapan pengembangan media serta uji coba baik One to One maupun skala besar yang telah dilakukan dengan mengacu pada nilai uji coba, maka dapat dinyatakan bahwa Multimedia Interaktif Diklat Listrik Aliran Atas yang dikembangkan memiliki kualitas yang baik menurut pengguna dan sudah dapat menunjang pembelajaran lebih baik lagi dan dapat 
digunakan sebagai media pembelajaran untuk menunjang proses diklat di BPTP Sofyan Hadi.

\section{UCAPAN TERIMA KASIH}

Dengan ini saya selaku pengembang mengucapkan banyak terima kasih kepada semua pihak yang membantu penelitian ini, terutama Dosen Pembimbing saya dan pihak internal lembaga PT Kereta Api Indonesia Persero yang telah bersedia memberikan akses kepada pengembang untuk melakukan penelitian ini.

\section{DAFTAR PUSTAKA}

Adam, steffi dan Muhammad T.S. 2015. "Pemanfaatan Media Pembelajaran Berbasis Teknologi Informasi Bagi Siswa Kelas X Sma Ananda Batam." CBIS Journal 3 No 2 (ISSN 2337-8794): 78-9o.

Aji, Wisnu Nugroho. 2016. "Model Pembelajaran Dick and Carrey Dalam Pembelajaran Bahasa Dan Sastra Indonesia." Kajian Linguistik Dan Sastra 1 (2): 119. https://doi.org/10.23917/kls.vii2.3631.

Bruce, 2011. 2013. "RAGAM MEDIA PEMBELAJARAN: Dari Pemanfaatan Media Sederhana Ke Penggunaan Multi Media." Journal of Chemical Information and Modeling 53 (9): 1689-99. https://doi.org/10.1017/CBO9781107415324.004.

Hidayat, and Nurasyiah. 2017. "PENGARUH DIKLAT (PENDIDIKAN DAN PELATIHAN) TERHADAP PRESTASI KERJA KARYAWAN DI BANK BPR ROKAN HULU.” Jurnal Ilmiah Cano Ekonomos 6 (1): $71-82$.

I. Rasyid, Rohani. 2018. "MANFAAT MEDIA DALAM PEMBELAJARAN." 96.

Ismail, Walid. M. 2017. "PENGEMBANGAN MEDIA PEMBELAJARAN INTERAKTIF BERBASIS GEOGEBRA DENGAN MODEL PENGEMBANGAN ADDIE (ANALYSIS, DESIGN, DEVELOPMENT, IMPLEMENTATION, EVALUATION) PADA MATERI GEOMETRI KELAS XI MIA SMA NEGERI 3 TAKALAR," 1-14.

Khurotin, Nurul, Tri Wulida Afrianty, Fakultas Ilmu Adminiatrasi, and Universitas Brawijaya. 2018. "Analisis Pelatihan Dan Pengembangan Sumber Daya Manusia Di Pt Beon Intermedia Cabang Malang." Jurnal Administrasi Bisnis 64 (1): 195203.
Kurniawan, Dian, Sinta Verawati Dewi, Jurusan Pendidikan, Matematika Fakultas, Keguruan Dan, Ilmu Pendidikan, and Universitas Siliwangi. 2017. "Pengembangan Perangkat Pembelajaran Dengan Media Screencast- OMatic Mata Kuliah Kalkulus 2 Menggunakan Model 4-D Thiagarajan." Jurnal Siliwangi 3 (1).

Mahnun, Nunu. 2012. "Media Pembelajaran (Kajian Terhadap Langkah-Langkah Pemilihan Media Dan Implementasinya Dalam Pembelajaran).” An-Nida' 37 (1): 27-35.

Nandi. 2006. "Jurnal ' GEA ' Ju Rusan Pendidikan Geografi Vol . 6 , No . 2 , Oktoner 2006” 6 (2): 19.

Setiawati, Popong. 2018. "Analisa Dan Perancangan Sistem Informasi Penyedia Lowongan Pekerjaan Yang Direkomendasi Berdasarkan Standar Kompetensi Kerja Nasional Indonesia ( Skkni )" 3: $136-47$.

Sujarwo. 2008. "Desain Sistem Pembelajaran," no. 2008: $\quad 1-18$. https://doi.org/10.1097/ICO.ooooooooooooo572

Sunhaji. 2013. "KONSEP PENDIDIKAN ORANG DEWASA." עלון הנוטע (1997):39-37. 66

Tafonao, Talizaro. 2018. "Peranan Media Pembelajaran Dalam Meningkatkan Minat Belajar Mahasiswa." Jurnal Komunikasi Pendidikan 2 (2): 103. https://doi.org/10.32585/jkp.v2i2.113.

Trisiana, Anita, and Wartoyo. 2016. "Desain Pengembangan Model Pembelajaran Pendidikan Kewarganegaraan Melalui Addie Model Untuk Meningkatkan Karakter Mahasiswa Di Universitas Slamet Riyadi Surakarta." PKn Progresif 11 (1): 312-30.

Winaryono, Dwiwidya, and Eko Budi Setiawan. 2015. "Pembangunan Aplikasi Pembelajaran Multimedia Interaktif Mata Pelajaran Fikih Kelas Iv Di Mi Miftahussalam Bandung Berbasis Desktop." Jurnal Ilmiah Informatika Komputa 1: 3.

SELAYANG PANDANG BALAI PELATIHAN TEKNIK PERKERETAAPIAN SOFYAN HADI. 2019, 22 Juli.

Tegeh, I Made. 2014, dkk. "MODEL PENELITIAN PENGEMBANGAN”, Yogyakarta: Graha Ilmu, 2014. 
Ragil Prasetyo Putro, et.al.| JPI/Vol.o4/No.o1/2021| H. 70 - 75

Anita, Ria. 2016, "PENGEMBANGAN MEDIA

PEMBELAJARAN TEKS ANEKDOT BERBASIS

ANIMASI PADA SISWA KELAS $\mathrm{X}$ SEKOLAH

MENENGAH KEJURUAN" (Lampung: Universitas

Lampung).

Pengertian dan Manfaat Media Pembelajaran, diakses

dari

"https://www.eurekapendidikan.com/2014/10/Pengerti an-dan-manfaat-media-pembelaiaran.html” pada tanggal 9 Januari 2020 pukul 21.31.

Media Interaktif, diakses dari

"http://nusantararent.com/artikel-multimedia-

interaktif-detail-45386" pada tanggal 24 Januari pukul

22.27 .

Sedarmayanti. 2013, "MANAJEMEN SUMBER DAYA

MANUSIA" (Bandung: Refika Aditama).

Pangestu, Bayu Aji, "PEMANFAATAN MEDIA

PEMBELAJARAN DALAM PENDIDIKAN" (Malang:

Universitas Negeri Malang). 